\title{
Limestone surfaces in built-up environment as indicators of atmospheric pollution
}

\author{
Alfred J. Vella, Alex Camilleri and Jean Pierre Tabone Adami \\ Department of Chemistry, University of Malta, Msida, Malta MSD 06
}

\begin{abstract}
The concentration of sulphate on limestone surfaces of the external walls of churches in Malta is shown to be related to their position and distance from a power station, the main local point source of sulphur dioxide pollution. Limestone powder collected from these surfaces was examined for the presence of particles which, under lowpower optical microscopy, appear as shiny black amorphous bodies which were interpreted as soot particles; the abundance of these bodies was expressed as a 'black particle count' (BPC). The degree of sulphation and BPC were shown to be correlated with each other and both appeared to be strongly dependent on the prevailing wind. The BPC contour map indicated an important contribution to the parameter from vehicular traffic. It is suggested that the degree of sulphation and BPC of limestone surfaces from the built environment should function as environmental indicators of the relative air quality with respect to $\mathrm{SO}_{2}$ and soot pollution. This data is possibly more accurately representative of the relative long-term air-quality status of different areas of habitation than that deduced from single or episodic measurements of atmospheric pollutant levels.
\end{abstract}

Keywords: Limestone, sulphation, sulphur dioxide, air pollution, soot

\section{Introduction}

To establish connections between the effects on health and the quality of air, the latter is frequently assessed from results obtained by direct measurements of specific pollutants in the ambient air of the population under study. These air samples are usually collected from one or more sites which are taken to be representative of the air being inhaled. It is clearly important that pollutant levels be determined for an adequate number of sites with sufficient frequency to permit reasonably good estimates of the actual exposure levels. Nonetheless, expense and other constraints frequently limit such measurements to single sites on an occasional basis; these results are then taken to represent typical exposure levels over wide areas. Local meteorological conditions, topography and/or the presence of tall buildings and chimneys can affect local concentrations of pollutants so that the measured values may actually not be typical of the general levels to which the population is exposed (UN-ECE, 1984).

In another approach to this problem, $\mathrm{SO}_{2}$ pollution in ambient air has been estimated by measuring alterations in the chemical composition of test surfaces which are sensitive to it. Ferris and Anderson (1962) used lead dioxide 'candles' whose surfaces convert into lead sulphate on exposure to the gas. The mass of lead sulphate formed per unit area per month is taken as a measure of the $\mathrm{SO}_{2}$ pollution in the air at the test site.

Calcite, the main constituent of limestone, reacts with 0269-4042 (C) 1996 Chapman \& Hall atmospheric $\mathrm{SO}_{2}$ to yield calcium sulphite which, under ambient conditions, quickly converts into gypsum. This mineral, being more soluble than calcite, would tend to be mobilized more easily by rainwater. Such a process contributes to weathering and decay of calcium carbonate rock exposed to $\mathrm{SO}_{2}$-polluted air. Such effects are believed to have caused the severe damage to limestone and marble monuments built centuries ago and found to have degenerated badly over the last few decades in cities with badly polluted atmospheres (UN-ECE, 1984). The aggressive effects of $\mathrm{SO}_{2}$ on limestone also include its tendency to dissolve calcite. Limestone surfaces exposed to aqueous sulphur oxide aerosols come under the influence of hydroxonium ions generated from reaction of $\mathrm{SO}_{2}$ (and possibly $\mathrm{SO}_{3}$ ) with water. In the presence of the hydroxonium ion, calcite is much more soluble than in pure water. Typically, runoff from carbonate-stone surfaces has a $\mathrm{pH}$ greater than 7 and experimental results suggest that the conversion of calcite to hydrogen carbonate is an important limestone-weathering process caused by acidic rain (Reddy, 1990). Limestone dissolution processes are further complicated by the fact that stone is capable of retaining dissolution products in its pore structure, thereby decreasing the rate of ion mobilization and consequent material loss from the stone (Reddy, 1990).

\section{The proposed hypothesis}

In regions with low rates of precipitation, the net loss of sulphate from limestone surfaces would tend to be a relatively inefficient process. Between rainfalls, dry deposition of sulphur oxides on limestone would 
build-up of calcium sulpliate in the surface the stone. During subsequent precipitation, a of this sulphate deposit will dissolve preferto calcite. The gypsum/calcite dissolution II depend strongly on the $\mathrm{pH}$ of rainwater ect that a fraction of the sulphate would esident in the surface; moreover, we hypothe$:$ the abundance of surface sulphate should 1e ambient atmospheric $\mathrm{SO}_{2}$ pollution levels za of the test surface and be discernible above .nd sulphate present naturally in the rock and osited continuously from sulphate-derived air. Limestone surfaces of man-made strucsuld thus function as environmental indicators ir quality with respect to $\mathrm{SO}_{2}$ pollution: the he degree of sulphation, the higher the exo $\mathrm{SO}_{2}$ of these structures and, by inference, heir inhabitants.

ling of fuels and combustible materials genot and other particulates which may settle on e surfaces in the vicinity. Chemical alteration urface involving partial dissolution and resation may help cement these particles into a rmanent association with the stone. The soblack crusts' found on the stonework and of severely polluted cities arise from such deposits. Limestone surfaces which lack visible encrustations may still host minor amounts of such particles in the stone fabric which would be visible under microscopic examination. Particles derived from burnt fuel would be distinguishable by their characteristic colour and morphology if present in light-coloured limestone crusts. It is further proposed that the abundance of such deposits should correlate with the extent of sulphation of the rock surface if both pollutants derive from the main source.

This paper presents and discusses the results obtained in a study aimed at testing this hypothesis, using the built-up environment on the Maltese islands.

\section{Description of the Malta environment}

Practically all built structures in the Maltese Islands, $96 \mathrm{~km}$ south of Sicily, are constructed from limestone. The climate is semi-arid and annual rainfall is low, typically $530 \mathrm{~mm}$ year ${ }^{-1}$, of which $87.5 \%$ falls during the winter (Chetcuti et al., 1992).

The limestone used in the building trade is a porous, fine-grained biomicrite composed almost wholly of calcitic tests of globigerinid planktonic foraminifera; the stone ranges in colour from yellow to pale grey.

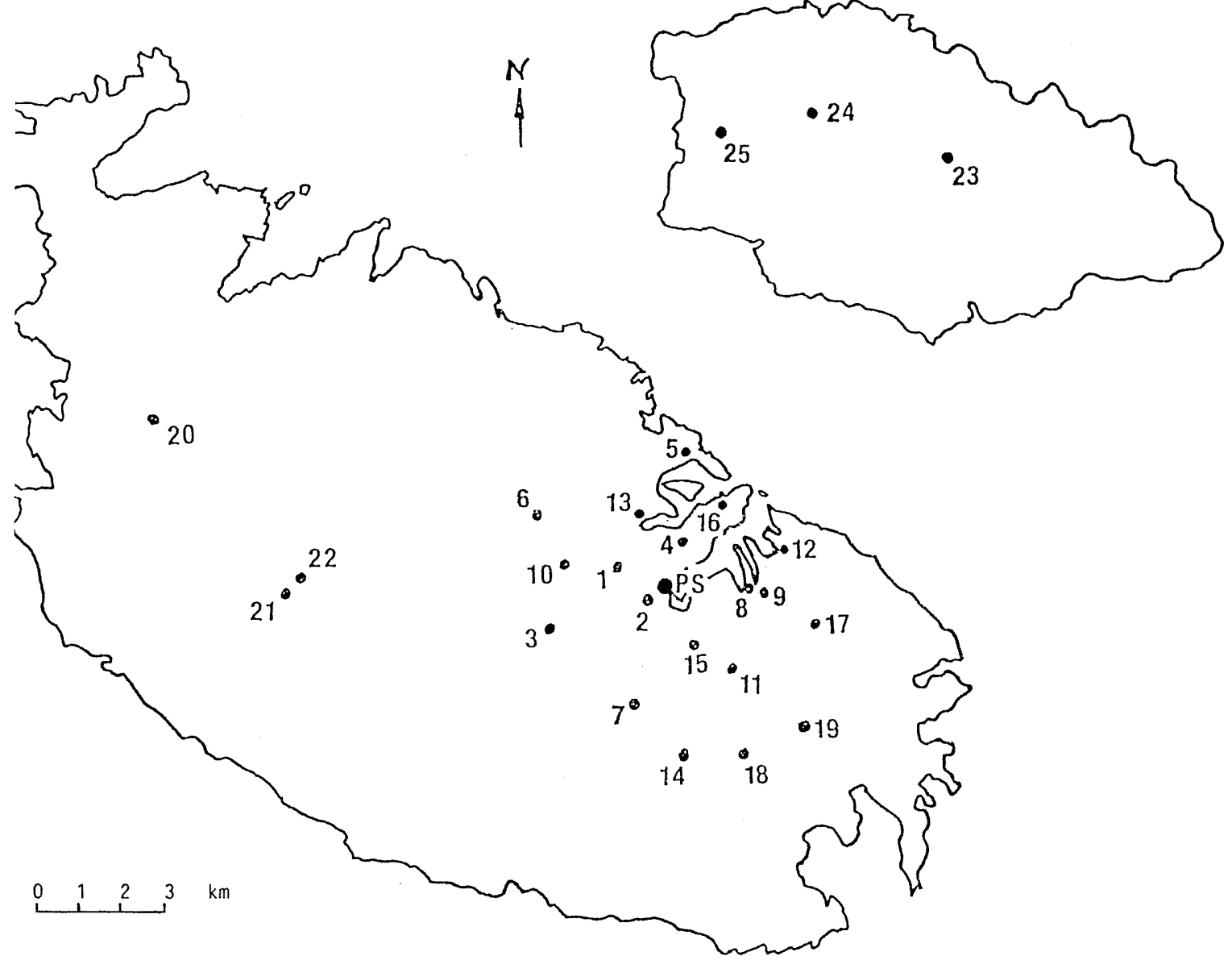
1 . 
The material is quarried from the Lower Member of the late Oligocene/early Miocene Globigerina Limestone Formation which outcrops on both Malta and Gozo.

The major source of atmospheric $\mathrm{SO}_{2}$ pollution in Malta is the power station at Marsa (Figure 1). The station uses both hard coal and fuel oil as fuels; the consumption rate is about 260000 tonnes of coal and 230000 tonnes of fuel oil per year. It is estimated that about 17000 tonnes of $\mathrm{SO}_{2}$ were emitted from the Marsa station in 1990 (Vella et al., 1993). The station is not equipped with flue gas desulphurizing equipment. A new power station at Delimara came on stream in 1991; this facility is oil-fired and is currently also contributing towards the ambient $\mathrm{SO}_{2}$ although its effects on the built environment are, to date, probably minor by comparison with those from the Marsa station. The contribution to the atmospheric $\mathrm{SO}_{2}$ load by automotive traffic in Malta is estimated at about 600 tonnes year-1 (Vella et al., 1993).

Note: The use of coal at the Marsa power station has very recently been discontinued.

\section{Materials and Methods}

External walls of several churches built in Malta and Gozo were chosen as the tests surfaces. All the churches selected for study were built before the construction of the Marsa power station which is about 50 years old and most are over 100 years old. Figure 1 shows the location of the churches and that of the Marsa power station.

Limestone powder was scraped off the surface of stones at the level of the bell towers and care was taken to exclude stone surfaces which appeared to have been recently repaired or which had been plastered over. Lichen-covered surfaces were also avoided. An area of $100 \mathrm{~cm}^{2}$ was lightly scraped with a knife edge to a depth not exceeding $0.5 \mathrm{~mm}$ : an approximately constant mass of powder was collected from each surface. The powder was stored in labelled polythene bags pending analysis. Two such areas separated by several meters from each other were sampled from each church building.

A weighed amount (100-200 mg) of stone was dissolved in hydrochloric acid and the resultant suspension was filtered. The residue was washed thoroughly with distilled deionised water and inspected under a low-power microscope for the presence of grains of zalcium sulphate identified by their colour and crystal abit. Wherever this material was observed the exseriment was repeated with a lower amount of stone owder. The filtrate, including washings, was anaysed for its sulphate content using a turbidimetric echnique with barium chloride as precipitant. The bsorbance was measured at $440 \mathrm{~nm}$ in a double beam
Perkin Elmer Lambda 3B spectrophotometer using a reference blank solution prepared from the filtrate. A calibration Beer plot was linear over the range 0.0 to $160 \mathrm{mg} \mathrm{SO}_{4}{ }^{2-} \mathrm{L}^{-1}$. The determination was repeated for concordant results.

Samples of limestone powder were analysed for the presence of particles which, under low-power microscopy and using reflected light, appear as shiny, amorphous black bodies. These bodies were interpreted as soot particles which originate from combustion processes mainly associated with the power station. A 'black particle count' (BPC) for the rock surface was determined as follows. The stone powder was pressed between two glass slides and examined by reflection optical microscopy at low magnification. The BPC was obtained by counting black particles appearing in the field of view. This was repeated three times with different fields of view and a mean value was calculated as the BPC of the limestone crust.

\section{Results and Discussion}

Table 1 shows the sulphate abundance, expressed as mass percentage $\mathrm{SO}_{3}$ with respect to whole rock and corresponding black particle counts for each of the 25 churches. The two entries (1) and (2) represent mean results for the two samples taken from each church

Table 1 Mass percentage of sulphate (as $\mathrm{SO}_{3}$ ) and black particle count (BPC) in surface limestone from church walls in Malta and Gozo.

\begin{tabular}{lllrr}
\hline Locality & \multicolumn{2}{c}{$\% \mathrm{SO}_{3}$} & \multicolumn{2}{c}{$\mathrm{BPC}$} \\
\cline { 2 - 5 } & $(1)$ & $(2)$ & $(1)$ & $(2)$ \\
\hline 1 Hamrun & 3.1 & 3.4 & 8 & 10 \\
2 Marsa & 2.4 & 4.5 & 17 & 35 \\
3 Qormi & 1.1 & 1.8 & 18 & 12 \\
4 Floriana & 1.1 & 1.8 & 22 & 21 \\
5 Sliema & 0.45 & 3.2 & 3 & 8 \\
6 Birkirkara & 0.60 & 1.1 & 7 & 8 \\
7 Luqa & 2.6 & 1.7 & 8 & 4 \\
8 Senglea & 0.51 & 1.1 & 24 & 24 \\
9 Bormla & 1.2 & 0.63 & 10 & 13 \\
10 Santa Venera & 1.5 & 0.97 & 2 & 4 \\
11 Tarxien & 2.2 & 1.1 & 5 & 5 \\
12 Kalkara & 0.55 & 0.55 & 11 & 9 \\
13 Msida & 1.0 & 1.2 & 3 & 7 \\
14 Gudja & 0.50 & 0.45 & 11 & 6 \\
15 Paola & 5.2 & 9.7 & 20 & 24 \\
16 Valletta & 1.4 & 0.18 & 5 & 8 \\
17 Zabbar & 2.1 & 6.3 & 3 & 5 \\
18 Ghaxaq & 1.7 & 1.2 & 8 & 8 \\
19 Zejtun & 1.0 & 2.0 & 7 & 8 \\
20 Mgarr & 0.19 & 0.19 & 7 & 9 \\
21 Rabat & 0.91 & 0.79 & 8 & 14 \\
22 Mdina & 0.93 & 1.0 & 17 & 8 \\
23 Xaghra & 0.12 & 0.49 & 16 & 19 \\
24 Ghasri & 0.19 & 0.025 & 4 & 5 \\
25 San Lawrenz & 0.025 & 0.070 & 1 & 1 \\
\hline
\end{tabular}




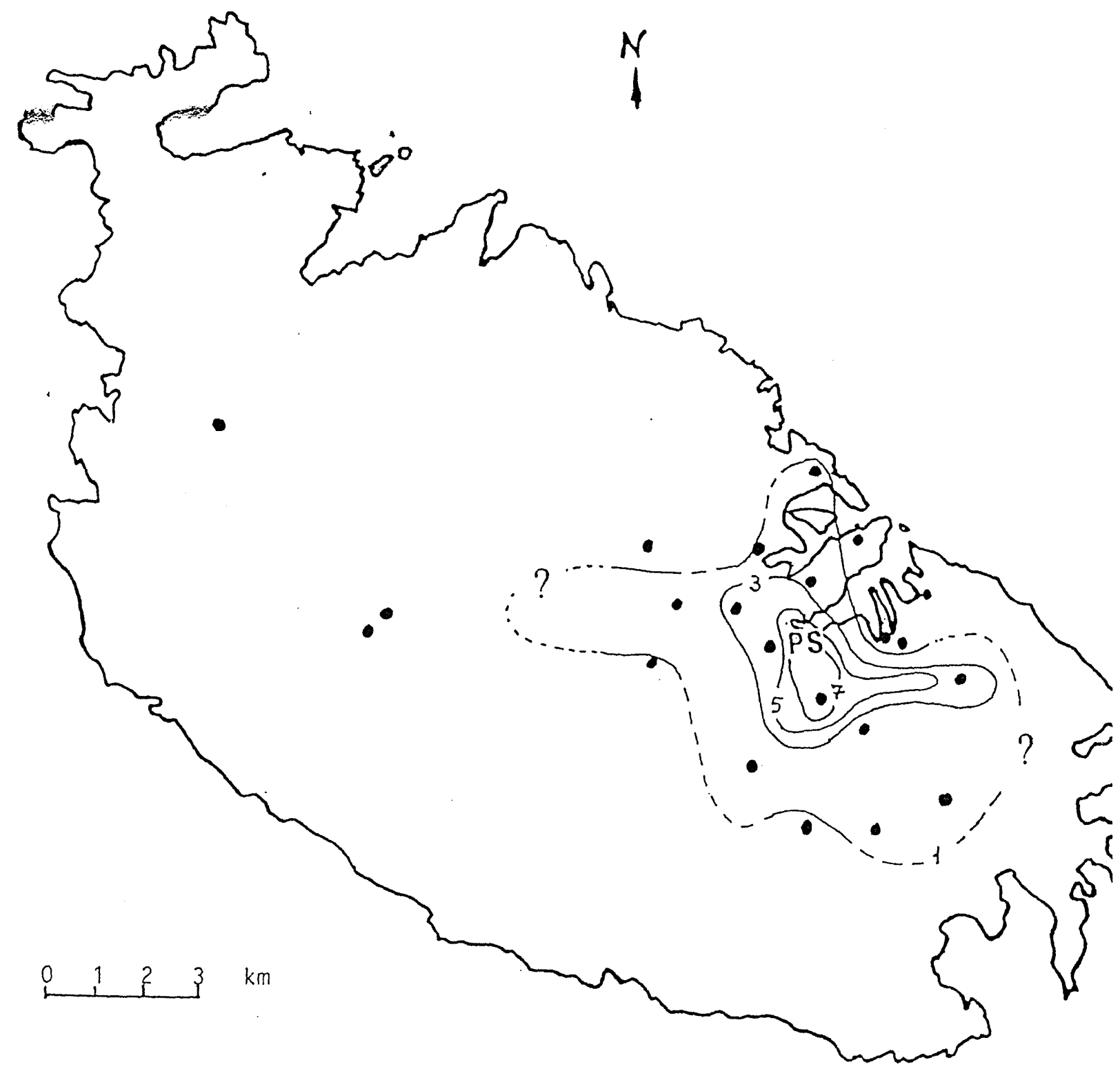

Figure 2 Contour map showing sulphate content (as $\% \mathrm{SO}_{3}$ ) on church limestone surfaces.

building.

The sulphate content of freshly quarried rock from the Lower Globigerina Limestone varies between 0.07 and $0.4 \% \mathrm{SO}_{3}$ with a median value of $0.10 \% \mathrm{SO}_{3}$ (Camilleri and Tabone Adami, 1992). A sulphate content higher than $0.4 \%\left(\right.$ as $\left.\mathrm{SO}_{3}\right)$ can therefore be taken as evidence of sulphation by anthropogenic sulphur oxides. Except for the Mgarr church (locality 20 ), which is $13 \mathrm{~km}$ away from the Marsa power station, all surface samples from the Malta group were found to contain substantially higher sulphate than that naturally present in the rock. On the other hand, there was no evidence of surface sulphation of the Gozo churches.

One would expect the degree of sulphation of surfaces of buildings to depend not only on the distance of the building from the power station but also on its bearing with respect to it. The results obtained support these expectations.

The contour map in Figure 2 was drawn by taking the mean of the percentage $\mathrm{SO}_{3}$ values for each of the two sampling areas in each site. It can be seen that (a) generally, the extent of sulphation decreases with increasing distance from the Marsa station, (b) the sulphation contour lines are not symmetrical about the power station as centre but that there are preferred directions of sulphate pollution, and (c) the greatest sulphation values occur south to south-east of the power station site.

Clearly the directions of prevailing winds play a determinative role in the distribution of air pollution originating at the power station. Figure 3 is the wind rose for Malta and shows the percentage frequencies of wind direction and speed based on meteorological 


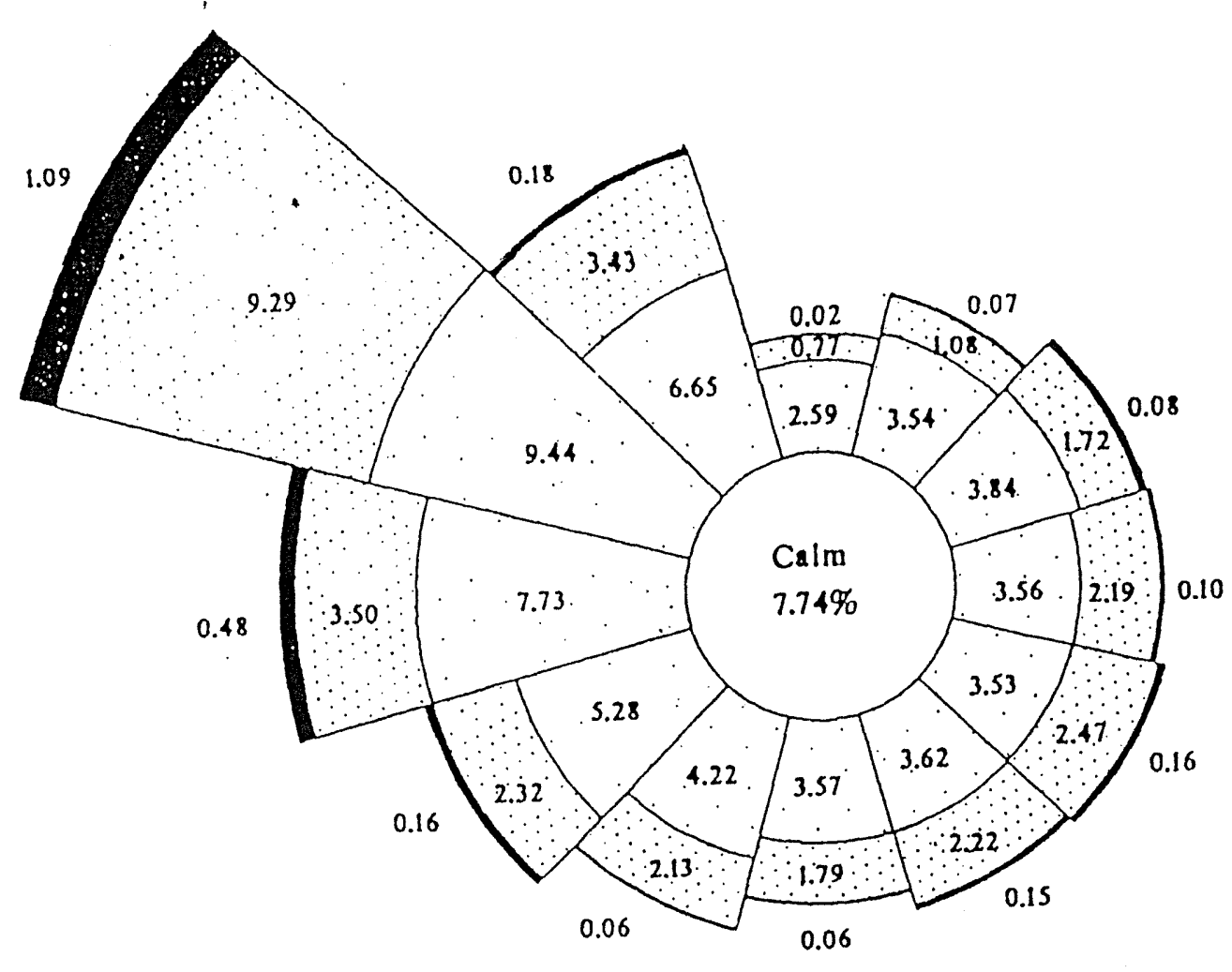

Figure 3 Wind rose showing percentage frequencies of mean wind speeds and directions for the whole year over the period 1958-1987. The length of each radiating arm represents the wind fiequency and the diameter of the central circle

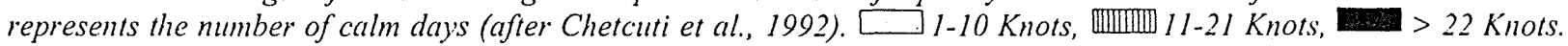

data for the period 1958 to 1987 (Chetcuti et al., 1992). The preferred direction for sulphation shown in Figure 2 correlates well with the prevalence and strength of north-westerly winds which transport pollution towards the south and south-east of the power station.

Figure 4 shows the contour map of black particle counts. The highest BPC values are centred around and lie very close to the power station: this clearly indicates that effluents from this source do represent the main contribution to soot in Malta air. The BPC distribution is not, however, apparently as strongly directional as sulphation and moreover it seems to favour a general westerly direction, although, admittedly, the contours (shown in dashed lines) are here more speculative than normal in view of the scarcity of data; the south-easterly prevalence evident in the sulphation map does not emerge. We suggest that vehicular traffic, and especially diesel engines (Acres, 1992), may be an additional but delocalized source of black soot particles in Malta. This source of pollution may be more important in the central areas of Malta, west of the power station, since this is where the mainroad network and the heaviest traffic is to be found. This could explain the extension westwards of the 5 to $15 \mathrm{BPC}$ contour lines in Figure 4 and also possibly that of the $1 \% \mathrm{SO}_{3}$ contour line evident in Figure 2.

Table 1 shows that, of the three Gozo sites, Xaghra church is anomalous in having a BPC value which is high in relation to that of the other Gozo (and Malta) sites. The sulphate concentration is within the naturally-occurring range for the limestone and does not point to a significant impact from an anthropogenic sulphur source. It is unlikely that this local high in the $\mathrm{BPC}$ is related to vehicular traffic since this island is much less urbanized than Malta. The anomaly is probably explained by the presence, $2 \mathrm{~km}$ north of Xaghra, of the main municipal dumping site in Gozo. Combustion of wastes in such dumps gives rise to frequent emissions containing abundant soot and smoke; in view of the low sulphation value, it would appear that sulphur oxides are not among the main emissions from this particular dump.

The extent of sulphation in limestone surfaces due to air pollution can only be properly assessed if the naturally occurring sulphate content of the rock is known. If this is not known, or if different limestones are used in the buildings surveyed, the technique can still be employed but it would require taking control samples at depth by drilling. In preliminary investigations, we found that sulphation and BPC values decrease rapidly with depth and become representative of the geochemical baseline values a few centimetres from the exposed limestone surface.

We conclude that the degree of sulphation and soot particle counts of limestone surfaces in the built environment can serve as useful indicators of atmospheric $\mathrm{SO}_{2}$ pollution. Determining sulphation levels 


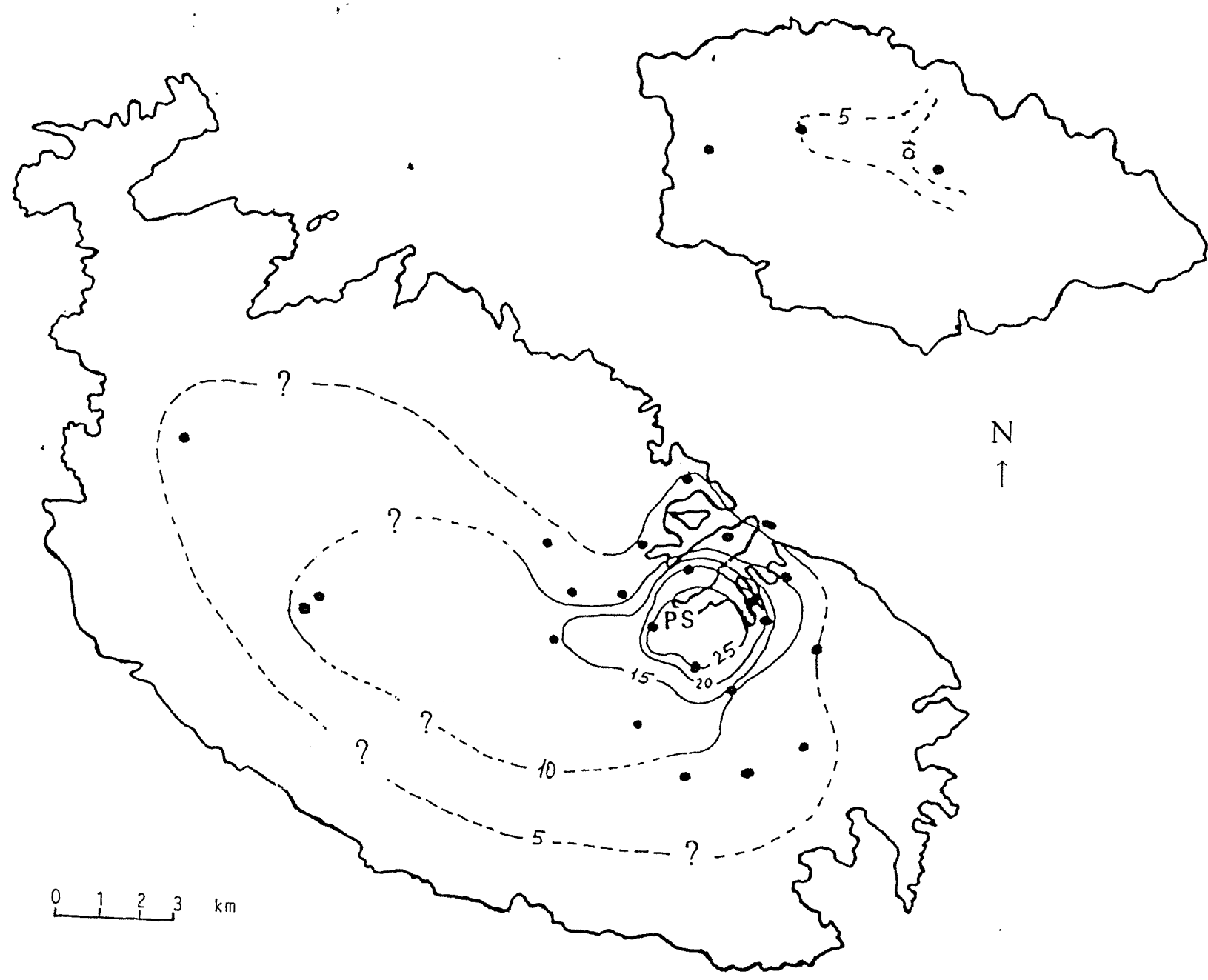

Figure 4 Contour map showing black particle count on church limestone surfaces.

and BPCs for the same test surface provides an important data set for environmental health studies in view of the established synergism between $\mathrm{SO}_{2}$ and particulate pollution. Obviously, the technique affords a 'snapshot' of the relative pollution status of the areas surveyed and it does not provide actual ambient $\mathrm{SO}_{2}$ or particulate concentrations in air. Indeed, while the technique may in principle be adopted for monitoring purposes, it is less convenient than that employing direct-reading instruments. However, limestone surface sulphate concentrations and $\mathrm{BPC}$ values from the built environment should be more accurately representative of the relative long-term air-quality status of different areas of habitation than that deduced from single or episodic measurements of atmospheric pollutant levels. Therefore, such data could be very useful in epidemiological studies. In addition, the technique may be employed without the support of expensive equipment. Clearly, if the sample analysis time is reduced by the use of, for example, X-ray fluorescence spectrometry for elemental sulphur concentrations, then, the number of data points can be considerably increased with resultant better definition of the pollution profile.

\section{References}

Acres, G.J.K. 1992. Catalyst systems for emission control from motor vehicles. In: Harrison, R.M. (ed), Pollution. Causes, Effects and Controls, 2nd edition, pp. 221-236. Royal Society of Chemistry, Cambridge.

Camilleri, A. and Tabone Adami, J.P. 1992. Geochemical study of soil facies in Lower Globigerina Limestone, Malta. Unpublished. University of Malta, Malta.

Chetcuti, D., Buhagiar, A., Schembri, P.J. and Ventura, F. 1992. The Climate of the Maltese Islands: a Review. University of Malta, Malta.

Ferris, B.G. and Anderson, D.O. 1962. The prevalence of chronic respiratory disease in a New Hampshire town. American Review of Respiratory Disease, 86, 165-177.

Reddy, M. 1990. Acid rain and air pollution effects on carbonate-stone: dissolution-runoff experiments. In: Zezza, F. (ed.) The Conservation of Monuments in the Mediterranean Basin, pp. 359-364. Grafo, Brescia, Italy.

UN-ECE. 1984. Air Pollution Studies 1: Airborne Sulphur Pollution, p. 103 and pp. 58-98. United Nations, New York.

Vella, A.J., Caruana, S. and Demanuele, J. 1993. Atmospheric sulphur dioxide in Malta: a preliminary study. Maltese Medical Journal, 5(2), 34-38.

[Manuscript 366: received October 18, 1994 and accepted after revision on December 7, 1995.] 